\title{
Teatro x la identidad: nuevos formatos, la misma búsqueda
}

\section{Silvina Díaz}

Desde sus inicios ${ }^{1}$, Teatro $\mathrm{x}$ la identidad -movimiento teatral de actores, dramaturgos, directores, coreógrafos, técnicos y productores- se propuso como un espacio aglutinador de diversas poéticas y de una variedad de formatos estéticos que implican distintos modos de pensar y expresar el reclamo político por la identidad y la memoria. Partiendo de la concepción del arte como herramienta de transformación sociopolítica, sus hacedores se plantearon el objetivo de acompañar a las Abuelas de Plaza de Mayo en la búsqueda de los nietos y nietas apropiados durante la dictadura militar. Como puede leerse en una suerte de manifiesto elaborado por sus protagonistas, el movimiento se originó "en la profunda necesidad de articular legítimos mecanismos de defensa contra la brutalidad y el horror que significa el delito de apropiación de bebés y niños y la sustitución de sus identidades de un modo organizado y sistemático por parte de la última dictadura cívico- militar argentina." ${ }^{2}$. Las obras del ciclo pretenden ofrecer una respuesta colectiva a las búsquedas de identidad, en tanto las historias singulares forman parte inevitablemente de una construcción social, de una vivencia profundamente arraigada en nuestro imaginario cultural. En este contexto, la denuncia pública y la exploración de la memoria aparecen como acciones reparadoras, concretas y pragmáticas.

El 2019 fue un año sumamente activo para la agrupación. Además de presentar la VII edición de Idénticos, se realizó el Festival de Teatro x la identidad, cuyas obras continuaron luego su temporada en el Teatro El Nacional. Por último, Teatro x la Identidad Itinerante realizó más de cincuenta funciones en distintas instituciones educativas, organizaciones sociales, municipios y plazas con el propósito de llegar a públicos de diferentes edades y realidades sociales. Tanto Idénticos como el Festival contaron con un apoyo masivo de público y con el acompañamiento de las Abuelas y de nietas y nietos recuperados, que reafirmaron la importancia de perseverar en la búsqueda. Las puestas se exhibieron también en el auditorio de La casa por la Identidad, del Centro Cultural Haroldo Conti (ex ESMA), incluyendo en esa ocasión una selección de obras para niños/as.

1. Teatro x la identidad, asociación civil sin fines de lucro, se originó a partir del estreno de A propósito de la duda, de Patricia Zangaro, con dirección de Daniel Fanego (2000) y dio a conocer su primer ciclo en 2001, ocasión en que se exhibieron cuarenta y una obras en diecisiete salas.

2. Las citas corresponden al sitio web del movimiento: (https://teatroxlaidentidad.net) 
En 2020, cuando Teatro $x$ la identidad cumplió 20 años de existencia, se ratifica desde el sitio web la necesidad y el derecho esencial a la restitución de la identidad, renovando el interés en estimular a los jóvenes que aún la desconocen: "Teatroxlaidentidad cumple 20 años buscando junto a las queridas Abuelas de Plaza de Mayo, a los nietos y nietas apropiados durante la dictadura cívico-militar. Este año nos toca acompañarlas respetando el aislamiento al que nos obliga la pandemia pero con el deseo intacto de seguir buscándolos para que vuelvan a casa".

En un periodo tan particular como el que atravesamos, ante la imposibilidad del encuentro y ante la ausencia de los cuerpos en convivio (Dubatti, 2007), los organizadores del ciclo apelaron a tres estrategias diferentes. Por un lado, la repetición de Idénticos en su VII edición, correspondiente al año anterior, por el canal de youtube del Teatro Nacional Cervantes -Cervantes Online - que les permitió llegar a un mayor número de espectadores. Por otro lado, la creación de Ocho formas de identidad y de Teatro x la identidad en el aire a partir de las herramientas que proveen las nuevas tecnologías, para ser exhibidos en plataformas digitales. Las tres ediciones contaron con el apoyo del Ministerio de Cultura de la Nación, del Instituto Nacional del Teatro y de PROTEATRO.

Idénticos consistió en una serie de micromonólogos que respondieron a una convocatoria abierta y cuya selección estuvo a cargo de Mauricio Kartun y Daniel Veronese. El evento comenzaba con una canción de Julia Morgado y la lectura de una carta a cargo de Pablo Echarri, en la que se expresaba "No saber quién es uno mismo es el peor de los exilios: el exilio de la propia historia. Y la aceptación resignada de esta mentira es una claudicación inaceptable. No. La mentira siempre es evitable, siempre podemos reconocerla y combatirla". Manteniendo una de las constantes distintivas de las obras del ciclo, los actores y las actrices se presentan al público después de sus respectivas intervenciones diciendo su nombre y su apellido, para agregar: "y puedo decirlo porque sé quién soy". Ciertamente el nombre constituye la primera señal identitaria y se asume aquí "como la representación sustitutiva que busca recuperar los vínculos de sangre deshechos". En este sentido, "el nombre recupera la lucha por la identidad, por la reinscripción de la historia, transformando a las obras que lo ponen en juego en un cuerpo de resistencia que busca la recuperación de un lugar crítico y de transformación para el sujeto" (Arreche, s/f).

Por su parte, los diez podcasts El día después, que componen el formato Teatro x la identidad en el aire, consisten en grabaciones sonoras de breves episodios ficcionales escritos e interpretados por reconocidos actores y actrices, a los que podía accederse a través de las redes sociales y de las programaciones radiales. Se trató, en este caso, de una invitación a reflexionar desde el humor sobre la situación del aislamiento y de lo que podría suceder luego de la pandemia a nivel individual y social.

Mientras que en Ocho formas de identidad, formato también concebido y realizado durante el aislamiento, se apelaba a las redes sociales con la finalidad de "seguir creando medios que expresen la identidad". Esta edición, a cargo de Mariela

Asencio, Paula Marull y Román Podolsky, se planteó explícitamente el propósito de "continuar con la búsqueda de las nietas y nietos de las queridas Abuelas de Plaza de Mayo e instalar la premisa que nos dejaron hace ya muchos años: en una sociedad que se pregunta por su identidad, a nosotras nos es más fácil encontrar a nuestros nietos". Como resultado de la convocatoria "sumate a teatroxlaidentidad compartiendo la tuya" ${ }^{3}$, difundida en las redes sociales, se presentaron una serie de monólogos y textos

3. En la convocatoria a formar parte de esta edición podía leerse: "Existen distintas formas de expresar lo que somos y distintas maneras de abrirle paso a nuestra identidad para dejar que se manifieste. 
breves, que oscilan entre los tres y los nueve minutos, inspirados en determinados ejes temáticos como modos de contar y expresar la identidad.

La primera parte constó de treinta y dos trabajos que versaban sobre cuatro ítems: objetos, textos, música y comida. Mientras que los veinticuatro trabajos que formaron parte de la segunda etapa giraban en torno al tema de las sexualidades, las maestras y los maestros, la ropa y los viajes. Por último, en el mes de diciembre se ofreció Ocho formas de identidad. La yapa, que reunía aquellos trabajos que habían obtenido menciones especiales.

Los tópicos más transitados, que fueron abordados desde las más variadas estrategias compositivas, organizadas siempre en torno al relato testimonial como recurso principal, se vinculan con la infancia como un mundo confortable y placentero y especialmente con los seres queridos que la poblaron, que marcaron a fuego la propia vida: los padres, los abuelos, los hermanos, los amigos. Afirma Leonor Arfuch, a propósito de la idealización de los recuerdos, que en el espacio subjetivo que supone la indagación histórica del pasado desde el ejercicio de la memoria individual surge inevitablemente "la autoficción, un género híbrido, a veces cercano a la novela, donde la marca autobiográfica se diluye en la tercera persona o en otro personaje sin pretensión de una "verdad" referencial" (Arfuch, 2016: 547)4.

En este sentido, en Batatitas en almíbar por ejemplo, uno de los episodios del ciclo, la reconstrucción de la historia del abuelo del protagonista, que vendía papas y batatas en un puesto de la feria barrial, del modo en que su abuela preparaba las batatas en almíbar y de las reuniones familiares en torno a ese manjar, aparece como uno de los caminos posibles para reconocer marcas identitarias y afectivas esenciales. En Una camiseta con el número 2 , en cambio, la pregunta por el valor que adquieren ciertos objetos en la propia vida -en este caso una prenda de vestir- da lugar a la reflexión sobre las complicidades y los sobreentendidos que caracterizaron la relación madrehijo. Mientras que en Los siete peniques se evoca la figura paterna recorriendo las páginas de un libro que representa entrañablemente la afectividad de ese vínculo y que esconde "un reclamo sordo: la necesidad de su abrazo".

Por su parte, en Entre dos tapas y un mundo, perteneciente a la misma serie -Textos- se revisitan algunos libros que poblaron la infancia y la adolescencia tamizando de emociones la cotidianeidad "en esas siestas de verano, en el zaguán fresco de la casa, bajo la sombra de los plátanos en la vereda". Imágenes que, a través de su potencia sensorial, nos sumergen automáticamente en esas vivencias, en las fantasías y los sueños que estimula la lectura.

En Volviendo de la playa la protagonista revive también un verano de su niñez -ilustrado con fotos y fragmentos de video que alternan con imágenes de la actualidad-: el regreso de la playa de la mano de su padre, la primera salida al cine con una amiga, la redacción escolar en la que "pretendían decirnos qué teníamos que desear". Del mismo modo, se invocan paisajes tan apreciados, tan recurrentes en nuestras vidas, que ya no se encuentran en el exterior sino que nos constituyen y forman parte de nuestra propia identidad. (Cordillera oriental).

¿Cuánto influyen los objetos, las canciones, las comidas, los textos en tu vida? ¿Cómo nos cuentan estas cosas a la hora de repensar la identidad?"

(https://cultura.ute.org.ar/8-formas-de-identidad-convocatoria/)

4. Observa Arfuch en este sentido, que no se trata ya "de dar cuenta de la experiencia del pasado en términos de la más rotunda presencia -el cuerpo propio sometido a tortura, vejación, persecución-, se trata justamente de hacer presente la ausencia como dato esencial de la identidad, de hacer de la afirmación pública de la filiación -como búsqueda incierta, como protesta o como rebeldía- un gesto político." (2016: 549). 
Lejos de recordar el pasado con un afán nostálgico, lo que se propone en todos los episodios es hacerlo dialogar con la actualidad, volver a descubrirlo como un cimiento estable desde donde repensar quiénes somos hoy. Con respecto a la infancia, es Arfuchs nuevamente quien sostiene que "el retorno a ese tiempo cercano o lejano, fantaseado o fantasmático, forma parte indisociable de nuestra experiencia. Allí anidan claves que dejan su impronta en el devenir -sin condicionarlo en términos absolutos- y también un núcleo resistente de nostalgia que involucra los seres y las cosas (...). Infancia y memoria parecen así enlazarse en una relación particular, donde la imagen evocada se plasma en el presente de la enunciación trayendo consigo una carga afectiva que lo transfigura: como toda memoria, es siempre presente" (Arfuch, 2016: 545-546).

Desde luego que en la mayoría de las obras que, a lo largo de su existencia, puse en escena Teatro $\mathrm{x}$ la identidad el pasado rememorado no constituye un mundo idílico sino más bien un tiempo oscuro, signado por vínculos rotos y desarticulados, profundamente atravesado por la violencia y la represión política. El ejercicio de la memoria diseña entonces, a partir de lo vivido, de lo que pudo averiguarse, de la propia experiencia y de la experiencia ajena que se torna propia -la de los seres queridos- un camino posible para hacer visible y palpable el trauma, para entender y repensar el presente. En este sentido la recuperación de la infancia viene a mostrarnos, justamente, "que nunca habrá un fin de los relatos en la experiencia traumática de un colectivo, por más que ciertas voluntades o los mecanismos complejos de la vida política pretendan desactivar en algún caso esa perseverancia del pasado". (Arfuch, 550). 


\section{Q Bibliografía}

"Arfuch, L. (2016). “Narrativas en el país de la infancia”. Alea vol. 18 n³, Río de Janeiro, sept./dic., pp. 544-560.

»Arreche, A. (s/f). "El teatro y lo político. Teatro x la identidad (2001- 2012). Derrotero de un debate identitario". Disponible en https://teatroxlaidentidad.net/ material/investigaciones/Txl-Investigacion-AArreche-EITeatroYLoPolitico

»Dubatti, J. (2007). Filosofía del teatro I. Convivio, experiencia, subjetividad. Buenos Aires: Atuel. 